\title{
Superior compliance with a neuromuscular training programme is associated with fewer ACL injuries and fewer acute knee injuries in female adolescent football players: secondary analysis of an RCT
}

\author{
Martin Hägglund, Isam Atroshi, Philippe Wagner and Markus Walden
}

\section{Linköping University Post Print}

\section{Tweet}

N.B.: When citing this work, cite the original article.

Original Publication:

Martin Hägglund, Isam Atroshi, Philippe Wagner and Markus Walden, Superior compliance with a neuromuscular training programme is associated with fewer ACL injuries and fewer acute knee injuries in female adolescent football players: secondary analysis of an RCT, 2013, British Journal of Sports Medicine, (47), 15, 974-979.

http://dx.doi.org/10.1136/bjsports-2013-092644

Copyright: BJSM

Postprint available at: Linköping University Electronic Press

http://urn.kb.se/resolve?urn=urn:nbn:se:liu:diva-101390 


\section{Superior compliance with a neuromuscular training programme is associated with fewer ACL injuries and fewer acute knee injuries in female adolescent football players: Secondary analysis of an RCT}

\section{Martin Hägglund, ${ }^{1}$ Isam Atroshi, ${ }^{2,3}$ Philippe Wagner, ${ }^{4}$ Markus Waldén ${ }^{3,5}$}

${ }^{1}$ Division of Physiotherapy, Department of Medical and Health Sciences, Linköping University, Linköping, Sweden

${ }^{2}$ Department of Clinical Sciences, Lund University, Lund, Sweden

${ }^{3}$ Department of Orthopaedics, Hässleholm-Kristianstad-Ystad Hospitals, Hässleholm, Sweden ${ }^{4}$ National Competence Centre for Musculoskeletal Disorders, Lund University, Lund, Sweden ${ }^{5}$ Division of Community Medicine, Department of Medical and Health Sciences, Linköping University, Linköping, Sweden

\section{Correspondence to}

Dr Martin Hägglund, Division of Physiotherapy, Department of Medical and Health Sciences, Linköping University, 58183 Linköping, Sweden. E-mail: martin.hagglund@ liu.se Tel: +46 101034232, Fax: +46 13351112 .

Word count: 3108 


\section{ABSTRACT}

Background Little is known about the influence of compliance with neuromuscular training (NMT) on the knee injury rate in football.

Aim To evaluate team and player compliance with a NMT programme in adolescent female football and to study the association between compliance and acute knee injury rates.

Methods Prospective cohort study based on a cluster randomised controlled trial on players aged 12-17 years with 184 intervention teams (2471 players) and 157 control teams (2085 players). Exposure and acute time loss knee injuries were recorded. Team and player compliance was recorded by the coaches on a player attendance form. The intervention group was divided into tertiles of compliance. Injury rates were compared by calculating rate ratios (RRs) and 95\% confidence intervals (CIs) using exact Poisson tests with the low-compliance tertile as reference. Seasonal compliance trends were analysed using linear regression. Results Players in the high-compliance tertile had an $88 \%$ reduction in the ACL injury rate (RR $0.12,95 \%$ CI 0.01 to 0.85 ), whereas the rate in the control group players was not significantly different from those in the low-compliance tertile (RR $0.77,95 \%$ CI 0.27 to 2.21). A significant deterioration occurred in both team ( $b=-3.0 \%$ per month, $95 \%$ CI -5.2 to 0.8 ) and player ( $b=-5.0 \%$ per month, $95 \% \mathrm{CI}-7.1$ to -2.9$)$ compliance over the season. Conclusions Players with high compliance with the NMT programme had significantly reduced ACL injury rate compared with players with low compliance. Significant deterioration in team and player compliance occurred over the season. 


\section{INTRODUCTION}

The anterior cruciate ligament (ACL) injury rate is more than two-fold higher in female football players than in their male counterparts, ${ }^{12}$ and adolescent females are especially at risk. $^{23}$ Numerous studies have evaluated the preventive effect of neuromuscular training (NMT) programmes in female football, ${ }^{4-14}$ and all except one ${ }^{5}$ targeted adolescents. In many of these studies the documentation of compliance with NMT has been inconsistent or incomplete, and when reported compliance is usually documented by the team coach on the exposure report form. ${ }^{411-14}$ Typically, the reported compliance has often been low to moderate in these studies, ${ }^{15}$ but it is often unclear whether it is based on a team or individual player level. It has therefore recently been suggested that both parts are essential since the overall compliance is the product of the team completion and player attendance rates. ${ }^{15}$

Of the 11 aforementioned studies, only one randomised controlled trial (RCT) ${ }^{14}$ and one nonrandomised controlled study ${ }^{10}$ have shown significant reductions of overall or non-contact ACL injuries in female adolescent footballers with NMT. Another recent RCT has shown a significant reduction of non-contact ACL injuries in a mixed sample of female high school basketball and football players. ${ }^{9}$ Besides low statistical power to break down injuries into different injury types, poor compliance is probably the other main reason why some studies show no preventive effect of their intervention. ${ }^{13}$ The importance of good compliance was recently underlined in a study that evaluated the influence of team and player compliance on injury rates in female adolescent football. ${ }^{16}$ In that study, teams and players were divided into compliance tertiles (high, intermediate and low). Players with high compliance had lower rates of injuries overall and acute injuries (no knee injury data reported) than players with intermediate compliance. However, when evaluated on team level, no differences in injury 
rates were observed between teams in the three compliance groups. It was speculated by the authors that the latter finding was due to large within-team variability in player compliance and considerable between-team variations in the exposure to football. Consequently, their findings indicate that reporting compliance exclusively on team level may be insufficient when studying the effect of NMT on injury rates.

The objectives of the present study were to evaluate both team and player compliance with a NMT programme in adolescent female football and to study the association between compliance and acute knee injury rates. Our hypothesis was that the NMT programme would have a greater preventive effect in teams and players with higher compliance than those with lower compliance. 


\section{MATERIALS AND METHODS}

This is a sub-study of a cluster RCT that evaluated the preventive effect of a 15-minute NMT programme (Knäkontroll, SISU Idrottsböcker ${ }^{\odot}$, Sweden, 2005) on acute knee injuries in female adolescent football players. ${ }^{14}$ The study design, the NMT programme and the main results of the RCT have been reported previously. ${ }^{14} 17$

\section{Study procedures}

Briefly, teams with players aged 12 to 17 years in eight Swedish districts were recruited. Data were collected during the competitive season (1 April to 31 October, 2009). Individual playing time for each training session and match was registered by the coach on a computerbased player attendance form. ${ }^{18}{ }^{19}$ Study designated physiotherapists $(n=68)$ and physicians $(n=8)$ served as medical support to the teams and assisted coaches with data collection and injury evaluation. A recordable acute knee injury was defined as an injury that had a sudden onset and led to a player being unable to fully participate in future training or match play (contusions excluded). ${ }^{14} 17$ ACL injury was defined as a first-time or recurrent partial or total rupture of the ligament either isolated or associated with concomitant injuries to the knee joint. $^{20}$

\section{Intervention}

At a pre-study meeting, a study therapist gave practical instructions of the NMT programme to one coach and one player from each intervention group team. Intervention team coaches also received a CD-ROM and a leaflet describing the exercises and were instructed to complete the NMT programme during the warm-up at two training sessions per week. 


\section{Team and player compliance}

For each training session, coaches documented whether the team completed the NMT programme (yes/no), as well as individual player participation on the player attendance form. This documentation enabled evaluation of both team and individual player compliance. ${ }^{15} 16$ To monitor the accuracy of the coach-reported compliance, study therapists were instructed to make two unannounced visits to each intervention team during the season; one during the first part (spring) and one during the second part (autumn). At the start of the season, coaches provided study therapists with a preliminary training schedule specifying the two weekly sessions during which the NMT programme was intended to be carried out. The study therapists were instructed to observe the beginning of the training session out of sight for the on-field coach and document the execution of the NMT programme (yes/no). Control group teams were instructed to carry out their usual training throughout the season, and none reported performing any NMT similar to the intervention programme at study inclusion.

\section{Statistical methods}

The primary outcome was ACL injury rate and the secondary outcomes were rates of any acute knee injury and severe knee injury (>4 weeks absence). ${ }^{14}{ }^{17}$ Descriptive continuous data for compliance are presented as mean with standard deviation (SD) and range. The rate of completed NMT programmes recorded during the study therapists' unannounced visits are presented as a proportion of the total number of eligible visits. Injury rates are presented as the number of injuries per $1000 \mathrm{~h}$ of exposure with $95 \%$ confidence intervals (CIs).

Using a similar approach employed in two previous studies, ${ }^{16}{ }^{21}$ teams and players (independent of team compliance) in the intervention group were stratified into tertiles of compliance (low, intermediate, and high) based on their mean number of weekly NMT 
sessions during the season. For players who incurred an acute knee injury or were censored (leaving the team for reasons other than acute knee injury), the mean number of weekly NMT sessions until injury or censoring were calculated in the player stratification. To enable stratification into the compliance groups, exposure and injury data were included starting from each team's and player's first NMT session during the study period (e.g. if a team started registration 1 April and had their first NMT session 8 April, data were included from 8 April and onwards). For the current analyses, this resulted in exclusion, from the original RCT's intervention group, ${ }^{14}$ of 8 players, 3921 training hours, 1427 match hours, and 2 acute knee injuries (1 patella subluxation, 1 lateral collateral ligament sprain).

Seasonal trend for team and player compliance with the NMT programme was analysed using linear regression with team compliance or player compliance (proportion of completed NMT programmes of total team and player training sessions, respectively) as dependent variable and month and compliance tertile as independent variables. The same approach was used to analyse seasonal trends for player training attendance rates (percentage of players attending training).

Injury rates in the groups were compared by calculating rate ratios and corresponding CIs using exact Poisson tests according to Blaker. ${ }^{22}$ For the outcomes acute knee injury and severe knee injury, adjustment for age, menarche, match frequency, and district (stratification factor) was done using Poisson regression. Owing to the small number of events adjustment for these factors was not possible for the primary outcome ACL injury. Possible cluster effects for club belonging were not considered in the analyses due to negligible intra-class correlations for all outcomes (ACL injury -0.0026 , severe knee injury -0.0003 , acute knee injury 0.0070). 
All tests were 2 -sided with a significance level of $\mathrm{p}<0.05$. Analyses were done using $\mathrm{R}$ (Version 2.15.0 R Foundation for Statistical Computing, Vienna, Austria). 


\section{RESULTS}

This sub-study comprised 184 teams (121 clubs) with 2471 players in the intervention group and 157 teams (109 clubs) with 2085 players in the control group. In total, 47 acute knee injuries in 46 players (7 ACL injuries in 7 players) in the intervention group and 47 acute knee injuries in 44 players (14 ACL injuries in 14 players) in the control group were included. Player attendance at training sessions was $71 \%$ in both groups.

\section{Team compliance}

The intervention group teams completed the NMT programme in 5244 (79\%) of the 6632 team training sessions, or as a mean 1.4 NMT sessions per week (table 1). Teams in the low, intermediate and high-compliance tertiles completed the NMT programme in $63 \%, 82 \%$ and $89 \%$ of team training sessions, respectively. Overall, a significant deterioration in compliance over the season $(b=-3.0 \%$ per month, $95 \% \mathrm{CI}-5.2$ to $-0.8, \mathrm{p}=0.010)$ was observed. This was more pronounced in the low-compliance tertile, while the trend in the high-compliance tertile remained fairly stable (figure 1).

\section{Player compliance}

Intervention group players completed, on average, 21 NMT sessions over the season, equivalent to 1.0 session per week (table 1). A significant deterioration in player compliance over the season $(b=-5.0 \%$ per month, $95 \%$ CI -7.1 to $-2.9, \mathrm{p}<0.001)$ was observed (figure 2 ). Similarly, player attendance at training sessions deteriorated over the season $(b=-2.0 \%$ per month, $95 \%$ CI -3.1 to $-0.9, p=0.001$ ), specifically in the intermediate (from $81 \%$ to $69 \%$ ) and low-compliance tertiles (from $70 \%$ to $41 \%$ ), while attendance rates in the high-compliance tertile remained more stable (from $91 \%$ to $86 \%$ ) (figure 3). 


\section{Compliance monitoring by study therapists}

Of the 368 planned unannounced visits (184 teams x 2 visits), 321 (87\%) could be evaluated regarding compliance with the NMT programme (47 sessions could not be evaluated due to team drop-out during the study or cancellation of the training session). The study therapists completed $284(88 \%)$ of the eligible visits and the NMT programme was initiated in 255 (90\%) of these sessions. Cross-matching of study therapists' forms with the coach report in the player attendance record showed identical registrations in $279(98 \%)$ of the visited training sessions; in 5 training sessions coaches had registered completion of the NMT programme but the study therapists reported no NMT during their visit.

\section{Injury rates}

At team compliance level, no significant differences in injury rates for any outcome were found between the low-compliance tertile and the intermediate or high-compliance tertiles or the control group (table 2). At player compliance level, the players in the high-compliance tertile had an $88 \%$ reduction in the ACL injury rate compared with the low-compliance tertile (table 2). Consistently, the intermediate and high-compliance tertiles had rate reductions of between $72-90 \%$ for severe knee injuries and acute knee injuries compared with the lowcompliance tertile. The adjusted analyses for the secondary outcomes gave similar results (data not shown). Similar or lower injury rates were seen in the control group compared with the low-compliance tertile at player compliance level. 


\section{DISCUSSION}

The principal finding in this study was that players with high compliance with the NMT programme had significantly reduced rates of ACL injury, severe knee injury and any acute knee injury compared with players with low compliance. Players in the low-compliance tertile had no protective effect at all, showing similar or even higher, injury rates than the control group performing no NMT programme. Additionally, significant deteriorations were seen in both team and player compliance over the season.

\section{Knee injury prevention}

The current study extends the recent literature that high compliance is a key factor in yielding significant reductions of ACL injuries with NMT programmes. ${ }^{15}$ In the main cluster RCT, we reported a $64 \%$ lower overall ACL injury rate in the intervention group compared with the control group. ${ }^{14}$ In this sub-study, the teams and players of the intervention group were categorised into compliance tertiles similar to the procedure in other recent studies. ${ }^{1621}$ Players in the high-compliance tertile had an $88 \%$ lower ACL injury rate compared with those in the low-compliance tertile. Additionally, and probably equally important, the ACL injury rate for players in the low-compliance tertile was not significantly different from that in the control group.

Significant reductions in the rates of severe knee injury and any acute knee injury ranging from $72 \%$ to $90 \%$ were also seen in the intermediate and high-compliance tertiles compared with the low-compliance tertile. Although data about knee injuries were not reported in two previous similar studies evaluating the association between compliance with NMT and injury 
rates in female youth football, ${ }^{1621}$ these two studies, consistent with our findings, reported the greatest preventive effect in the highest compliance tertile. Worth noting is that players in the low-compliance tertile in the present study had higher injury rates than the control group players. A possible explanation is that low-compliant players represent a sample of players with low motivation to physically prepare for sports and/or participated in teams where the coach had lesser interest in preventive training, which could lead to increased injury rates.

In accordance with a previous similar trial, ${ }^{16}$ no significant differences were seen in injury rates between teams belonging to the high, intermediate and the low-compliance tertiles. This probably reflects a low player attendance at training sessions, and thus also to NMT sessions, in some teams in the high and intermediate-compliance tertiles, and further highlights the importance of monitoring compliance at a player level in addition to team compliance.

\section{Compliance and monitoring}

The teams reported carrying out the NMT programme at $79 \%$ of all training sessions, which is similar to the rates reported in previous trials in youth football $(77-86 \%) .{ }^{1621}$ Delivery of the NMT programme to intervention group coaches included a pre-study instructional meeting, where a trained physiotherapist instructed coaches on proper exercise technique and on how to progress the players through the programme. Coaches also received a free CD-ROM and leaflet with exercise instructions. Interestingly, Steffen et al. ${ }^{21}$ recently concluded that such an approach was more effective in terms of increasing team compliance with a similar NMT programme (FIFA 11+) compared with a web-based only delivery. No additional benefits were seen in the sub-group that in addition to a pre-season coach workshop also had regular follow-ups by a physiotherapist at their training sessions. ${ }^{21}$ 
Despite the relatively high compliance with the NMT programme in the present study, team as well as player compliance deteriorated over the season, and this decrease was most pronounced in the low-compliance tertile. This tallies with recently published data from Norwegian girls' football that teams performed fewer NMT sessions in the second half of the season compared with the first half, with the decrease being most prominent in teams with the lowest compliance. ${ }^{16}$ This deterioration could reflect decreasing motivation among coaches to use the NMT programme throughout an entire season, although it should be noted that team compliance in the high and intermediate compliance tertiles was fairly consistent over the whole season. There is thus a need for further evaluation of motivational barriers and facilitators among coaches to ensure high compliance with this NMT programme over the entire season. Additionally, the decrease in player compliance in the later stages of the season also reflects a deterioration of player attendance at training sessions over the season. A similar decrease in player attendance rates was recently reported in a study on community Australian footballers, ${ }^{23}$ stressing the importance of encouraging players to attend formal training sessions in order to increase the reach of exercise interventions throughout the season.

The accuracy of the coach-reported compliance was monitored via unannounced visits by the study therapists, ${ }^{17}$ an approach later also used by others. ${ }^{21}$ Identical reports were found in $98 \%$ of cases indicating that the coach-reported compliance was reliable. In the other study in a similar setting, $85 \%$ of the NMT sessions were correctly reported. ${ }^{21}$

\section{Strengths and limitations}

The current sub-study study has several strengths. For example, it utilised a previously established approach in stratifying the intervention group into tertiles of compliance. ${ }^{1621}$ 
Moreover, compliance was evaluated from both team and player perspectives, which is essential since the overall compliance is dependent on both team completion of the NMT programme and attendance rates. ${ }^{15}$ Additionally, the large sample with more than 4500 players makes our study the first to evaluate the influence of compliance on knee injury rates specifically, which has not been possible in previous smaller studies. ${ }^{1621}$

This study also has a few important limitations. First, players were divided into compliance tertiles based on their weekly NMT session rate. This means that players who were injured early in the season may have been stratified into the intermediate or high-compliance tertiles based on a high weekly rate of NMT sessions up until the injury event, but having carried out only few actual NMT sessions. It can be argued that a preventive effect of NMT on acute knee injuries can only be seen after completion of up to a certain (unknown) number of sessions, making our method of stratification into compliance tertiles less valid. However, if anything, this will only have underestimated the preventive effect of being in the intermediate to high-compliance tertiles. Second, owing to the small number of ACL injuries it was not possible to compute adjusted rate ratios for the primary outcome. Consequently, only crude rate ratios are reported, which is similar to a previous study by Soligard et al. ${ }^{16}$ However, adjustment was possible for acute knee injuries and severe knee injuries and this analysis showed almost identical findings as the crude analysis. Third, training sessions in the control group were not monitored, and even though none of the control group coaches reported performing any NMT programme at study inclusion, we were not able to register possible contamination of the NMT intervention in the control group over the season. 


\section{Implications}

This study shows that effective prevention of acute knee injury is associated with high individual player compliance to NMT. Preventive measures are more likely to be effective when the intervention does not rely on an individual's behaviour modification, ${ }^{24}$ and by implementing NMT as a routine warm-up this will become an integrated part of football training and increase player compliance. Importantly, high player attendance at training sessions is also needed to achieve high player compliance. ${ }^{23}$ With this said, it is obvious that the coach is a key person in preventing knee injuries in female adolescent football players. Given the growing body of evidence that NMT programmes can effectively prevent lower limb injuries in adolescent athletes, ${ }^{8-10121421}$ it is essential to translate this knowledge to various stakeholders in youth sports. A recent study reported knowledge gaps in injury prevention among football coaches, adolescent players and parents, and the current evidence, ${ }^{25}$ showing that much work is still required. Finally, having the knowledge of effective preventive measures does not guarantee a change in behaviour, ${ }^{24}$ and studies evaluating intervention delivery and identifying motivators and barriers (among various sports stakeholders) to adopt and maintain NMT programmes over time are warranted. Such future evaluations could preferably be conducted using frameworks established for team sports, such as the RE-AIM Sports Setting Matrix. ${ }^{26}$ 


\section{Acknowledgements}

We thank all the coaches and players who participated in the study as well as the study therapists and study physicians constituting the medical support to the teams. Professor Per Renström, MD, PhD, Mrs Annica Näsmark, PT, and Mrs Anneli Gustafsson from the Swedish Football Association (FA) is gratefully acknowledged for study assistance as well as Mr Henrik Magnusson, MSc, for statistical advice and data handling.

\section{Contributor statement}

$\mathrm{MH}$, IA, and MW were responsible for the conception and design of the study. MH and MW coordinated the study and managed all aspects including data collection. PW conducted the analyses which were planned and checked with the co-authors. All authors contributed to the interpretation of findings and had full access to all data. MH and MW wrote the first draft of the paper which was critically revised by IA and PW. The final manuscript has been approved by all authors. MH and MW are study guarantors.

\section{Funding}

The study was financially supported by the Swedish FA and the Folksam Insurance Company. This research also received grants from the Swedish National Centre for Research in Sports and the Hässleholm Hospital.

\section{Competing interests}

MH and MW constituted the medical staff of the male under-19 national team of the Swedish FA between 2007 and 2011. 


\section{Ethics approval}

The study was approved by the regional ethical review board in Linköping (\# M197-08).

Players and parents or legal guardians gave individual written informed consent.

\section{Provenance and peer review}

Not commissioned; externally reviewed. 


\section{WHAT ARE THE NEW FINDINGS?}

- Female adolescent football players with high compliance with a 15-minute warm-up NMT programme had significantly reduced rates of ACL injury, severe knee injury and any acute knee injury compared with players with low compliance.

- Players with low compliance with the NMT programme had similar or even higher knee injury rates than players in the control group receiving no intervention.

- Significant deteriorations were seen in both team and player compliance over the season.

- Coach-reporting seems to be a reliable method to capture compliance with a NMT programme, with $98 \%$ of sessions having matched records between the coach and the unannounced visits by a study designated physiotherapist.

\section{HOW MIGHT IT IMPACT ON CLINICAL PRACTICE?}

- Considering the low training frequency and relatively low player attendance at training in youth female football teams, it is recommended that the NMT programme is implemented as a routine at all training sessions with the team to increase the reach among players. By monitoring attendance at training sessions, and completion of NMT among the players, coaches can ensure that players have sufficient compliance with NMT to gain a preventive effect. Coaches should also consider recommending players with low training attendance to carry out additional NMT training at home. 


\section{REFERENCES}

1. Prodromos CC, Han Y, Rogowski J, et al. A meta-analysis of the incidence of anterior cruciate ligament tears as a function of gender, sport, and a knee injury-reduction regimen. Arthroscopy 2007;23:1320-5.

2. Waldén M, Hägglund M, Werner J, et al. The epidemiology of anterior cruciate ligament injury in football (soccer): a review of the literature from a gender-related perspective. Knee Surg Sports Traumatol Arthrosc 2011;19:3-10.

3. Shea KG, Pfeiffer R, Wang JH, et al. Anterior cruciate ligament injury in pediatric and adolescent soccer players: an analysis of insurance data. J Pediatr Orthop 2004;24:623-8.

4. Emery CA, Meeuwisse WH. The effectiveness of a neuromuscular prevention strategy to reduce injuries in youth soccer: a cluster-randomised controlled trial. Br J Sports Med 2010;44:555-62.

5. Gilchrist J, Mandelbaum BR, Melancon $\mathrm{H}$, et al. A randomized controlled trial to prevent noncontact anterior cruciate ligament injury in female collegiate soccer players. Am J Sports Med 2008;36:1476-83.

6. Heidt RS Jr, Sweeterman LM, Carlonas RL, et al. Avoidance of soccer injuries with preseason conditioning. Am J Sports Med 2000;28:659-62.

7. Hewett TE, Lindenfeld TN, Riccobene JV, et al. The effect of neuromuscular training on the incidence of knee injury in female athletes. Am J Sports Med 1999;27:699-706.

8. Kiani A, Hellquist E, Ahlqvist K, et al. Prevention of soccer-related knee injuries in teenaged girls. Arch Intern Med 2010;170:43-9. 
9. LaBella CR, Huxford MR, Grissom J, et al. Effect of neuromuscular warm-up on injuries in female soccer and basketball athletes in urban public high schools: cluster randomized controlled trial. Arch Pediatr Adolesc Med 2011;165:1033-40.

10. Mandelbaum BR, Silvers HJ, Watanabe DS, et al. Effectiveness of a neuromuscular and proprioceptive training program in preventing anterior cruciate ligament injuries in female athletes. Am J Sports Med 2005;33:1003-10.

11. Pfeiffer RP, Shea KG, Roberts D, et al. Lack of effect of a knee ligament injury prevention program on the incidence of noncontact anterior cruciate ligament injury. $J$ Bone Joint Surg Am 2006;88:1769-74.

12. Soligard T, Myklebust G, Steffen K, et al. A comprehensive warm-up programme to prevent injuries in young female footballers: cluster randomised controlled trial. $B M J$ 2008;337:a2469.

13. Steffen K, Myklebust G, Olsen OE, et al. Preventing injuries in female youth football - a cluster-randomised controlled trial. Scand J Med Sci Sports 2008;18:605-14.

14. Waldén M, Atroshi I, Magnusson H, et al. Prevention of acute knee injuries in adolescent female football players: cluster randomised controlled trial. BMJ 2012;344:e3042.

15. Sugimoto D, Myer GD, Bush HM, et al. Compliance with neuromuscular training and anterior cruciate ligament injury risk reduction in female athletes: a meta-analysis. $J$ Athl Train 2012;47:714-23.

16. Soligard T, Nilstad A, Steffen K, et al. Compliance with a comprehensive warm-up programme to prevent injuries in youth football. Br J Sports Med 2010;44:787-93.

17. Hägglund M, Waldén M, Atroshi I. Preventing knee injuries in adolescent female football players - design of a cluster randomized controlled trial [NCT00894595]. BMC Musculoskeletal Disorders 2009;10:75. 
18. Fuller CW, Ekstrand J, Junge A, et al. Consensus statement on injury definitions and data collection procedures in studies of football (soccer) injuries. Br J Sports Med 2006;40:193-201.

19. Hägglund M, Waldén M, Bahr R, et al. Methods for epidemiological study of injuries to professional football players - developing the UEFA model. Br J Sports Med 2005;39:340-6.

20. Waldén M, Hägglund M, Magnusson $\mathrm{H}$, et al. Anterior cruciate ligament injury in elite football: a prospective three-cohort study. Knee Surg Sports Traumatol Arthrosc 2011;19:11-9.

21. Steffen K, Meeuwisse WH, Romiti M, et al. Evaluation of how different implementation strategies of an injury prevention programme (FIFA 11+) impact team adherence and injury risk in Canadian female youth football players: a clusterrandomised trial. Br J Sports Med 2013;47:480-7.

22. Blaker H. Confidence curves and improved exact confidence intervals for discrete distributions. Can J Statistics 2000;28:783-98.

23. Finch CF, Diamantopoulou K, Twomey DM, et al. The reach and adoption of a coachled exercise training programme in community football. Br J Sports Med 2013 Mar 12. [Epub ahead of print]

24. van Tiggelen D, Wickes S, Stevens V, et al. Effective prevention of sports injuries: a model integrating efficacy, efficiency, compliance and risk-taking behaviour. $\mathrm{Br} J$ Sports Med 2008;42:648-52.

25. Orr B, Brown C, Hemsing J, et al. Female soccer knee injury: observed knowledge gaps in injury prevention among players/parents/coaches and current evidence (the KNOW study). Scand J Med Sci Sports 2013;23:271-80. 
26. Finch CF, Donaldson A. A sports setting matrix for understanding the implementation context for community sport. Br J Sports Med 2010;44:973-8. 


\section{TABLE AND FIGURE LEGENDS}

Table 1 Intervention group team and player exposure and compliance data overall and stratified into high ( $\mathrm{n}=61$ teams, 831 players), intermediate ( $\mathrm{n}=60$ teams, 823 players) and low ( $\mathrm{n}=63$ teams, 817 players) compliance tertiles

Table 2 Injury rates among teams and players stratified into high ( $\mathrm{n}=61$ teams, 831 players), intermediate ( $\mathrm{n}=60$ teams, 823 players) and low ( $\mathrm{n}=63$ teams, 817 players) compliance tertiles of the intervention group and the control group ( $\mathrm{n}=157$ teams, 2085 players)

Figure 1 Team compliance with the neuromuscular training programme in the high, intermediate and low compliance tertiles of the intervention group over the season

Compliance is reported as the percentage of the total number of training sessions where the neuromuscular training (NMT) programme was carried out each month (number of team NMT sessions/number of team training sessions $\mathrm{x}$ 100). The low compliance in July is due to mid-season summer break from training and matches.

Figure 2 Player compliance with the neuromuscular training programme in the high, intermediate and low compliance tertiles of the intervention group over the season

Compliance is reported as the percentage of the total number of training sessions where the neuromuscular training (NMT) programme was carried out each month (number of player NMT sessions/number of total player training sessions $\mathrm{x}$ 100). The low compliance in July is due to mid-season summer break from training and matches.

Figure 3 Player training attendance rates in the high, intermediate and low compliance tertiles of the intervention group over the season 
Table 1 Intervention group team and player exposure and compliance data overall and stratified into high ( $n=61$ teams, 831 players), intermediate ( $n=60$ teams, 823 players) and low ( $\mathrm{n}=63$ teams, 817 players) compliance tertiles

\begin{tabular}{|lll|}
\hline & Teams & Players \\
\hline Mean no. of training sessions during season (SD, range) & $38(12,5-77)$ & $28(13,1-76)$ \\
Low compliance & $35(13,5-71)$ & $20(11,1-64)$ \\
Intermediate compliance & $39(10,20-66)$ & $28(10,1-69)$ \\
High compliance & $41(13,8-77)$ & $36(12,3-76)$ \\
Mean no. of matches during season (SD, range) & $19(8,1-50)$ & $16(8,0-56)^{*}$ \\
Low compliance & $18(7,1-41)$ & $13(8,0-41)$ \\
Intermediate compliance & $20(7,5-42)$ & $16(7,0-40)$ \\
High compliance & $20(9,3-50)$ & $18(9,0-56)$ \\
Mean no. of NMT sessions during season (SD, range) & $30(10,1-52)$ & $21(10,1-51)$ \\
Low compliance & $22(8,1-36)$ & $12(5,1-26)$ \\
Intermediate compliance & $32(6,17-48)$ & $22(6,1-37)$ \\
High compliance & $37(10,8-52)$ & $30(9,2-51)$ \\
Mean no. of NMT sessions per week (SD, range) & $1.4(0.3,0.3-2.0)$ & $1.0(0.4,0.0-2.1)$ \\
Low compliance & $1.1(0.2,0.3-1.3)$ & $0.6(0.2,0.0-0.9)$ \\
Intermediate compliance & $1.4(0.1,1.3-1.6)$ & $1.0(0.1,0.9-1.2)$ \\
High compliance & $1.7(0.1,1.6-2.0)$ & $1.4(0.2,1.2-2.1)$ \\
\hline
\end{tabular}

NMT denotes neuromuscular training

* Maximum number of player matches during season exceeds number of team matches because of matches played with other teams 
Table 2 Injury rates among teams and players stratified into high ( $\mathrm{n}=61$ teams, 831 players), intermediate ( $\mathrm{n}=60$ teams, 823 players) and low ( $\mathrm{n}=63$ teams, 817 players) compliance tertiles of the intervention group and the control group ( $\mathrm{n}=157$ teams, 2085 players)

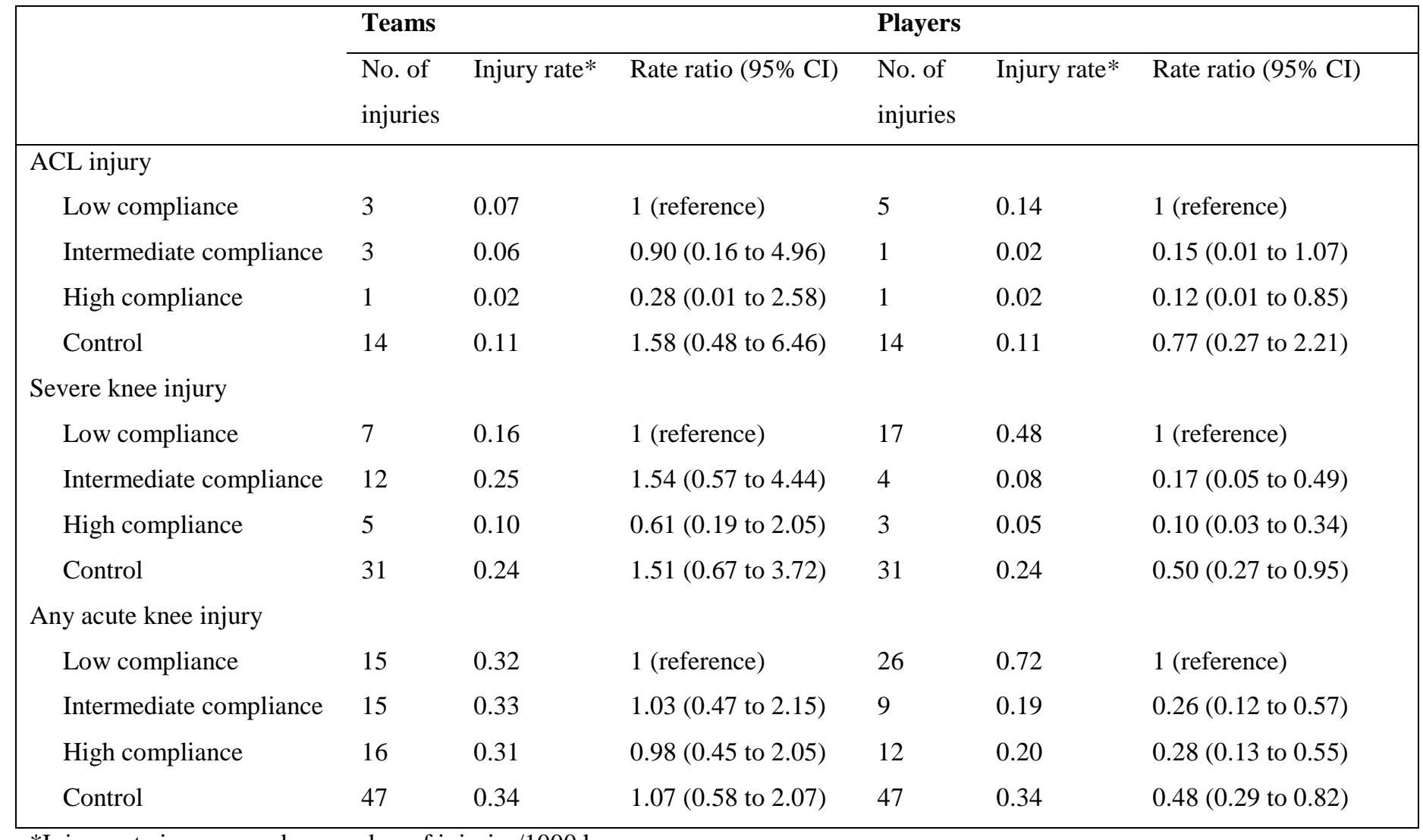

*Injury rate is expressed as number of injuries/1000 h. 


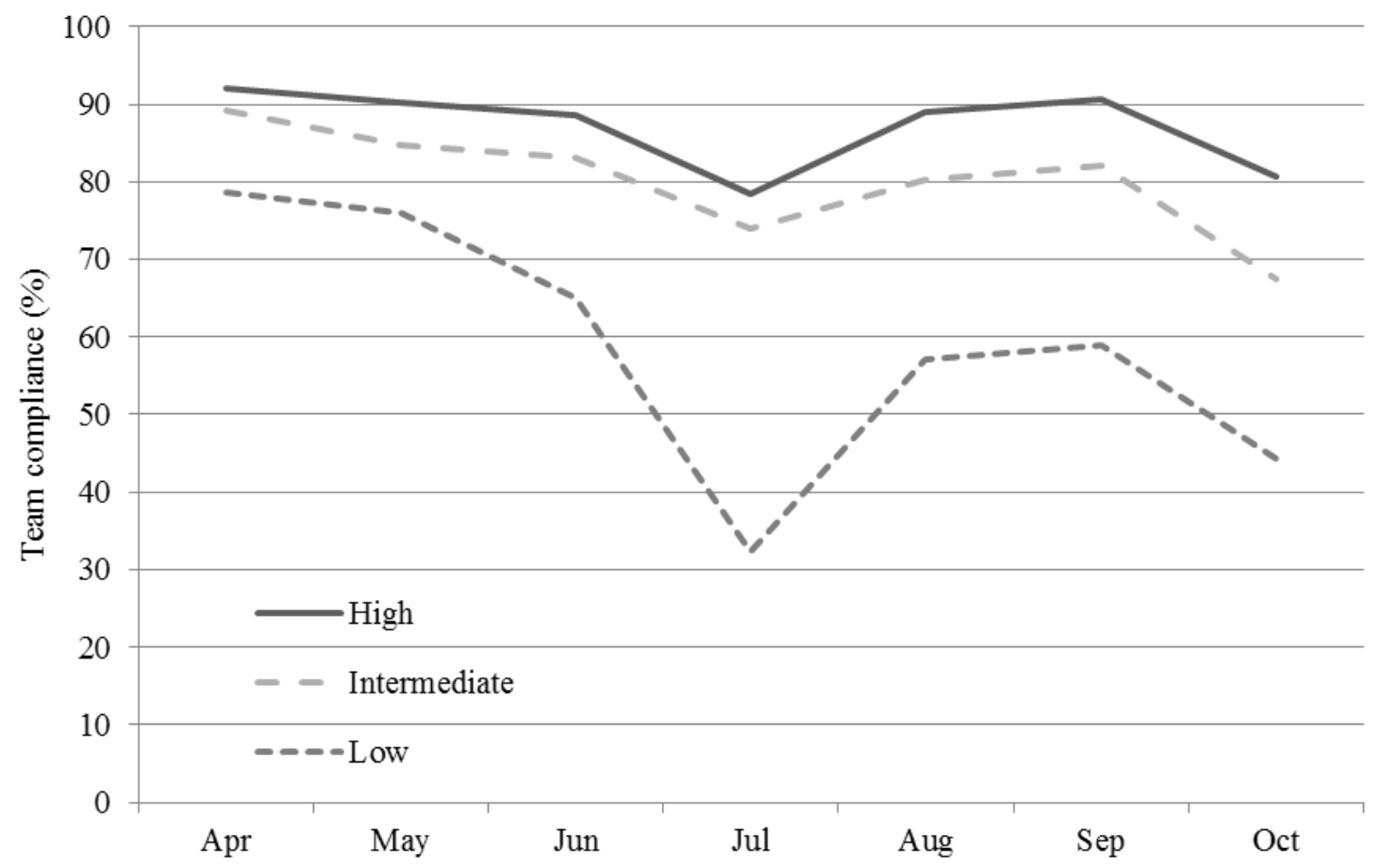

Figure 1 Team compliance with the neuromuscular training programme in the high, intermediate and low compliance tertiles of the intervention group over the season

Compliance is reported as the percentage of the total number of training sessions where the neuromuscular training (NMT) programme was carried out each month (number of team NMT sessions/number of team training sessions $\mathrm{x}$ 100). The low compliance in July is due to mid-season summer break from training and matches. 


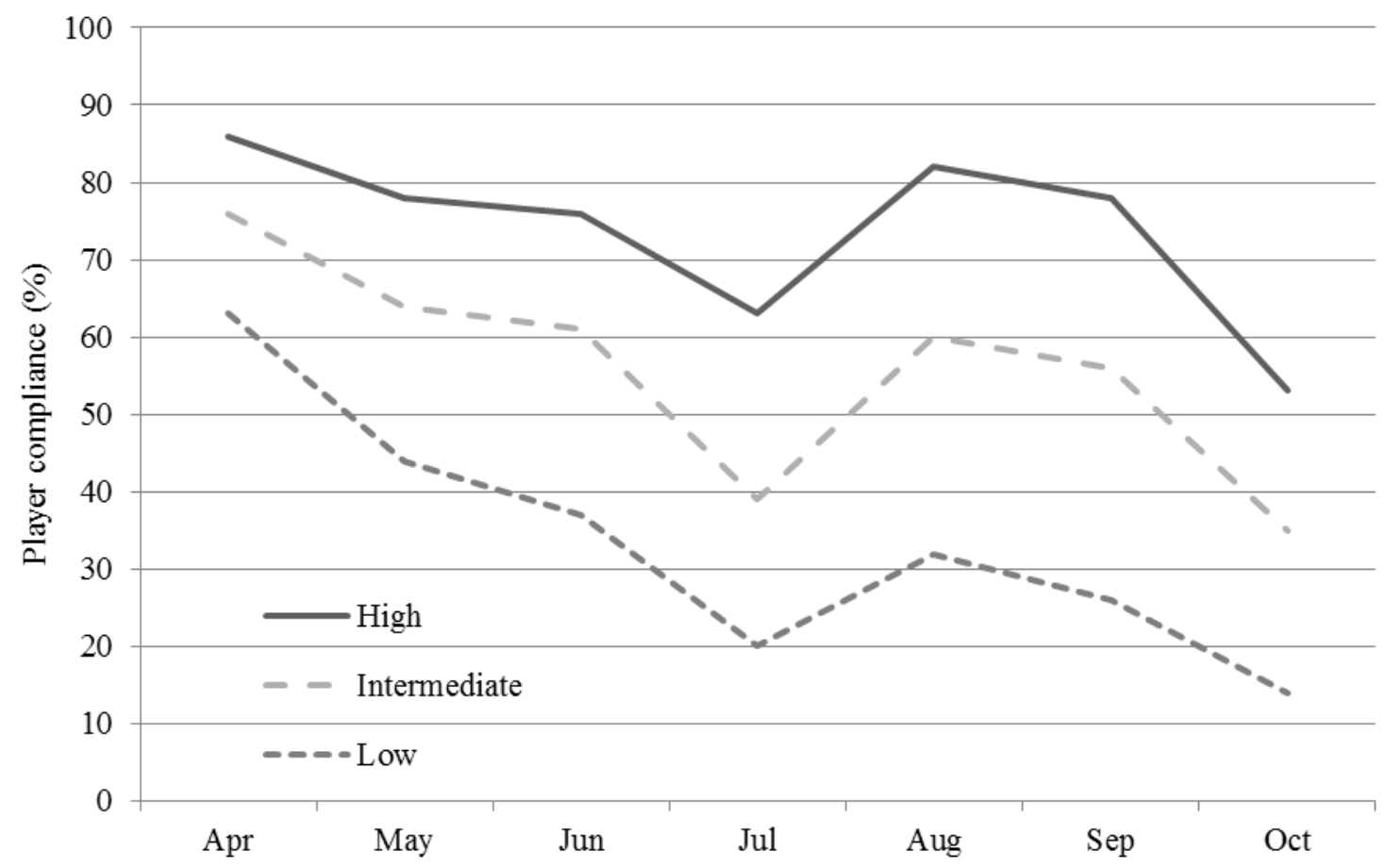

Figure 2 Player compliance with the neuromuscular training programme in the high, intermediate and low compliance tertiles of the intervention group over the season

Compliance is reported as the percentage of the total number of training sessions where the neuromuscular training (NMT) programme was carried out each month (number of player NMT sessions/number of total player training sessions $\mathrm{x}$ 100). The low compliance in July is due to mid-season summer break from training and matches. 


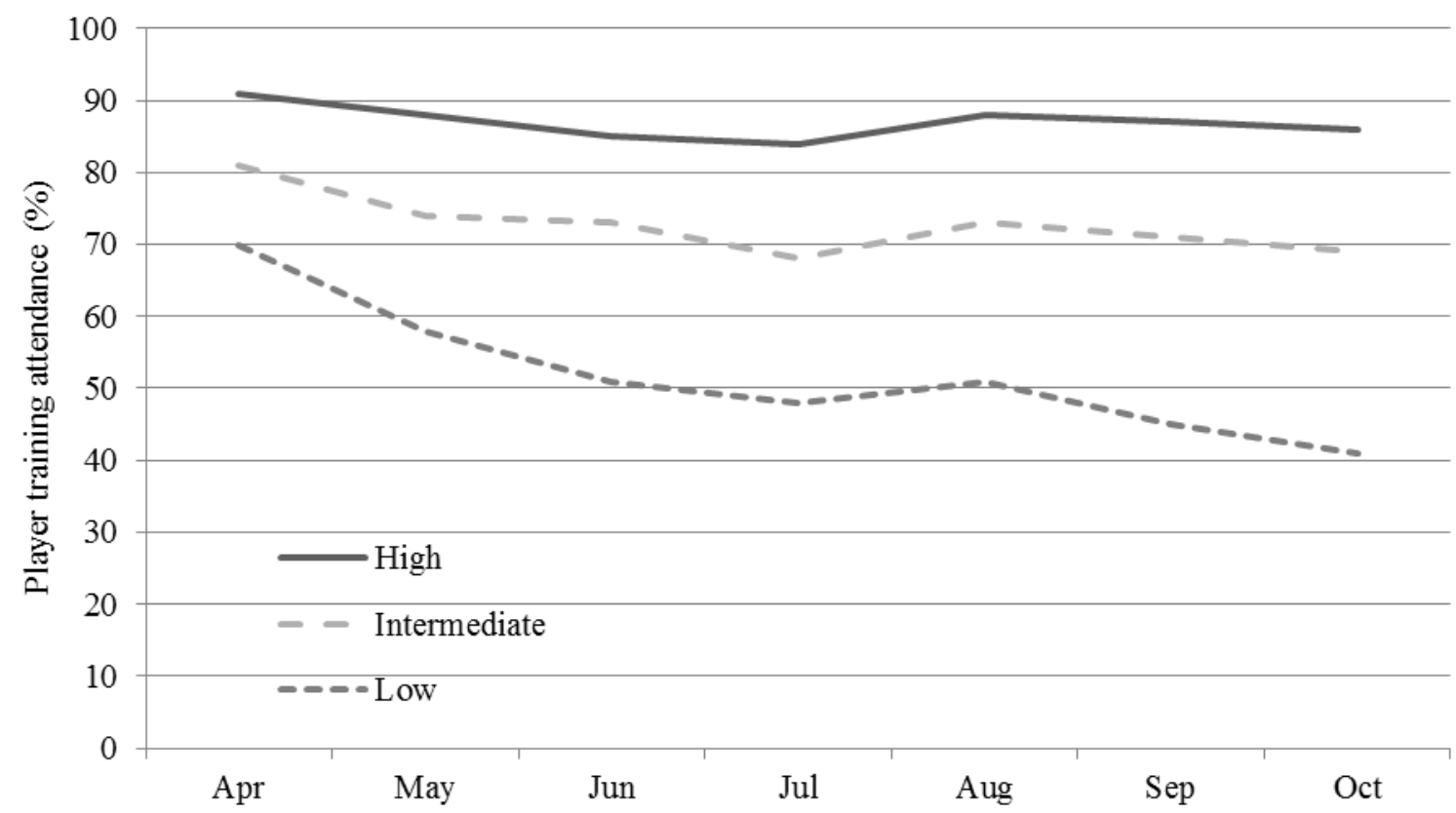

Figure 3 Player training attendance rates in the high, intermediate and low compliance tertiles of the intervention group over the season 